\title{
Gift Acceptance and Its Effect on Prescribing Behavior among Iraqi Specialist Physicians
}

\author{
Ehab Mudher Mikhael*, Dhulfiqar Nidhal Alhilali \\ Clinical Pharmacy Department, College of Pharmacy, Baghdad University, Baghdad, Iraq \\ Email: ehab_pharma84@yahoo.com, ibnalarabi@gmail.com
}

Received 30 April 2014; revised 3 June 2014; accepted 13 June 2014

Copyright (C) 2014 by authors and Scientific Research Publishing Inc.

This work is licensed under the Creative Commons Attribution International License (CC BY). http://creativecommons.org/licenses/by/4.0/

cc) (i) Open Access

\section{Abstract}

Background: The interaction between physicians and medical representatives (MRs) through gift offering is a common cause for conflicts of interest for physicians that negatively influence prescribing behaviors of physicians throughout the world. This study aimed to evaluate the interaction between MRs and Iraqi specialist physicians through the acceptance of MRs gifts and the effect of such acceptance on physician's prescribing patterns. Methods: A survey in a questionnaire format for specialist physicians was done during March-October 2013 in Iraq, Baghdad. The questionnaire involves four major parts regarding the approximate number of patients and medical representatives, gift acceptance, medical conferences, and prescribing pattern. Results: In Iraq specialist physicians were visited by $1-3 \mathrm{MRs} /$ day. $50 \%$ of the Iraqi physicians like to get the educational information by attending conferences outside Iraq. Regarding Gift acceptance, $41 \%$ of participated physicians showed a general acceptance to promotional gifts, and $91 \%$ of physicians accept low cost gifts but only $\mathbf{4 1 \%}$ of them accept high cost recreational gifts. Free samples were used by $59 \%$ of Iraqi physicians to treat some people. $77 \%$ of physicians prefer prescribing new medications, while more than $95 \%$ of participated physicians stated that they stop prescribing these new drugs either due to their ineffectiveness or due to their side effects. On the other hand physicians significantly change their prescribing behavior through shifting not only among generic drugs, but also from brand to generic drugs in their prescriptions. Gift acceptance is directly correlated with such shift and change in prescribing behavior. Conclusion: Iraqi physicians accept various types of gifts from pharmaceutical companies; this can influence physician prescribing pattern and result in early adoption to prescribe newly medications depending on promotional information even in absence of clinical evidence about the drug effectiveness or side effects, which may result in undesirable outcomes to the patient.

\section{Keywords}

Drug Promotion, Gifts, Prescribing Behavior

\footnotetext{
${ }^{*}$ Corresponding author.
} 


\section{Introduction}

A large budget of pharmaceutical companies is usually spent on drug promotion [1]. Physician targeted promotion through medical sale representatives (MRs) is one of the most common tactics that was adopted by pharmaceutical companies for promoting their products [2]-[4]. MRs use a variety of promotional tactics during their interaction with physicians like free drug samples, inviting physicians to educational conferences, giving brochures and sometimes gifts offering [5]. Although the interaction between physicians and MRs is inevitable and desirable, especially if MRs provide physicians with a sufficient and reliable information about their drugs, sometimes this interaction may create conflicts of interest for physicians [6] [7], this conflict of interest can result in a compromised ability of the physician to act for the benefit of a patient [8]. Gifts to physicians from pharmaceutical companies is one of the most evidenced factors that could lead to conflict of interest which may negatively influence prescribing behaviors of physicians, thus ultimately affect on the health of the patient [9].

So this study aimed to evaluate the interaction between MRs and specialist physicians through the acceptance of MRs gifts and the effect of such acceptance on physician's prescribing patterns.

\section{Methods}

A survey for specialist physicians was done during March-October 2013 in Iraq, Baghdad. A questionnaire format was given to 35 physicians however only 22 (response rate 63\%) agreed to participate in this study and fill in the questionnaire completely. The questionnaire involve questioning about the age, gender, occupation, specialty, besides four major parts of the questionnaire (as shown below) regarding the approximate number of patients and medical representatives, gift acceptance, medical conferences and meetings, and prescribing pattern. Statistical Analysis was done using SPSS version 12. Chi square test was used to test the significance of difference among categorical variables, whereas Pearson correlation was used to test the correlation between continuous variables. For doing correlations each answer was rated using suitable numbers, at which each positive answer by yes was rated as 1 and each negative answer by no was rated as zero, whereas answers that include many possibilities was rated as 1 for each answer with No, and 4 for highly positive answers (Yes always), while for the number of patients and MRs a mid value was used for each answer. P values less than 0.05 was considered significant.

\section{Results}

Participated physicians in this study were mostly males (77\%), non academic physicians (68\%), with different specialties as shown in Table 1 . This study (Table 2) showed that physicians visited by $1-3 \mathrm{MRs} / \mathrm{day}(\mathrm{P}=$ 0.005), but there is a non significant difference in the number of patients who visit clinics of different specialist physicians. The result of this study also showed that $50 \%$ of physicians like to get the educational information by attending conferences inside Iraq and 50\% outside Iraq. Meanwhile there is a non significant improvement (Table 3) for clinical knowledge by attending such conferences. Anyhow, physicians change their prescribing pattern sometimes $(\mathrm{P}=0.000)$ after attendance of such conferences.

Regarding Gift acceptance, this study (Table 4) showed that there is a non significant difference among physicians who accept gifts (41\%) and those who consider that behavior as non ethical and non acceptable (59\%). Mean while (91\%) of physicians accept low cost gifts (P value $<0.001$ ). In addition to that $68 \%$ of physicians consider low cost gifts acceptance at every visit of MR to their clinic is justifiable, yet it didn't achieve statistical significance. While for high cost gifts 59\% of participated physicians didn't accept such gifts (Figure 1), furthermore there is a significant agreement among physicians (73\%) that high cost gift at every visit of MR to the clinic is not justifiable (Figure 2). Regarding free samples this study (Figure 3) showed that there is a significant $(\mathrm{P}=0.007)$ usage of free samples by physicians $(59 \%)$ to treat some people, while only $5 \%$ use free sample un ethically for personal usage. Table 5 showed that there is a significant preference to prescribe new medications by most physicians $(77 \%)$, furthermore more than $95 \%$ of participated physicians $(\mathrm{P}<0.001)$ stated that they stop prescribing these new drugs either due to their ineffectiveness or due to their side effects. On the other hand the result of this study showed that physicians significantly $(\mathrm{P}<0.05)$ shift not only among generic drugs, but also from brand to generic drugs in their prescriptions.

This study showed (Table 6) that there is a direct positive correlation between many parameters including: number of medical representative with number of patient visiting the physician clinic, additionally when the 
Table 1. General demographic data.

\begin{tabular}{cc}
\hline Parameter & Value \\
Age (years) & $45.59 \pm 7.88$ \\
Gender M/F & $17 / 5$ \\
Occupation academic/hospital & $7 / 15$ \\
Specialty of participated physicians & 5 \\
Pediatric & 3 \\
Surgery & 3 \\
Gynecology & 2 \\
Nephrology & 1 \\
Endocrine & 1 \\
ENT & 1 \\
Dermatology & 1 \\
GIT & 1 \\
Hematology & 1 \\
Ophthalmology & 1 \\
Internal medicine & 1 \\
Cardiology & 1 \\
& Radiology \\
\end{tabular}

Table 2. Number of patients and MRs who visit the physician's clinic.

\begin{tabular}{|c|c|c|c|c|c|}
\hline Parameter & A & B & $\mathrm{C}$ & $\mathrm{D}$ & $\mathrm{P}$ value \\
\hline Number of patients & $3(14 \%)$ & 5 (23\%) & $10(45 \%)$ & $4(18 \%)$ & 0.152 \\
\hline Number of medical representatives & $8(36 \%)$ & $11(50 \%)$ & $2(9 \%)$ & $1(5 \%)$ & 0.005 \\
\hline
\end{tabular}

$\mathrm{A}=(<5$ patients/day and $<1 \mathrm{MRs} /$ day $), \mathrm{B}=(5-10$ patients/day and $1-3 \mathrm{MRs} /$ day $) ; \mathrm{C}=(10-20$ patients/day and $3-5$ MRs/day), D = ( $>20$ patients/day and $>5$ MRs/day).

Table 3. Conferences' effect on physicians' knowledge and prescribing pattern.

\begin{tabular}{lccccc}
\hline \multicolumn{1}{c}{ Parameter } & Yes, always & Yes, many times & Yes, some times & Not at all & P value \\
\hline $\begin{array}{l}\text { Improvement of medical knowledge by meetings and } \\
\text { conferences that sponsored by drug companies }\end{array}$ & $4(18 \%)$ & $7(32 \%)$ & $9(41 \%)$ & $2(9 \%)$ & 0.152 \\
$\begin{array}{l}\text { changing clinical practice after attending sponsored } \\
\text { conferences and meetings }\end{array}$ & $0(0 \%)$ & $1(5 \%)$ & $19(86 \%)$ & $2(9 \%)$ & 0.000 \\
\hline
\end{tabular}

Table 4. Physicians' opinions regarding gift acceptance.

\begin{tabular}{|c|c|c|c|}
\hline \multirow{2}{*}{ The question } & \multicolumn{2}{|c|}{ The answer } & \multirow{2}{*}{$P$ value } \\
\hline & Yes & No & \\
\hline Are gifts acceptable? & $9(41 \%)$ & $13(59 \%)$ & 0.393 \\
\hline Are low cost gifts acceptable? e.g. pens & $20(91 \%)$ & $2(9 \%)$ & 0.000 \\
\hline Are low cost gifts justifiable when given to the physician at every visit of the MRs? & $12(55 \%)$ & $10(45 \%)$ & 0.669 \\
\hline Are high cost recreational gifts (e.g. TV, Mobile, Ipad...) are justifiable in drug promotion? & $9(41 \%)$ & $13(59 \%)$ & 0.393 \\
\hline Are high cost gifts at every visit of MRs to the physician justifiable? & $6(27 \%)$ & $16(73 \%)$ & 0.033 \\
\hline
\end{tabular}




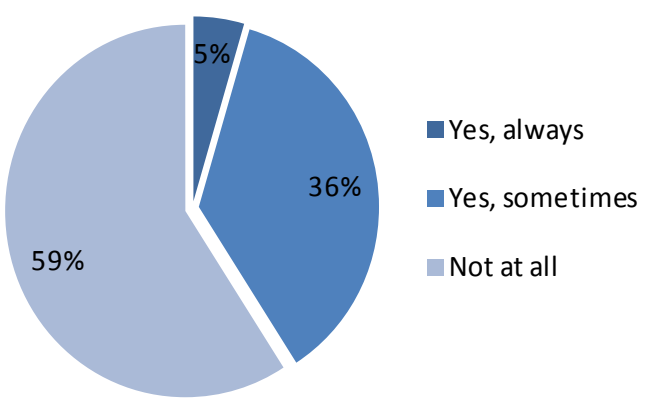

Figure 1. Physicians acceptance of high cost gifts.

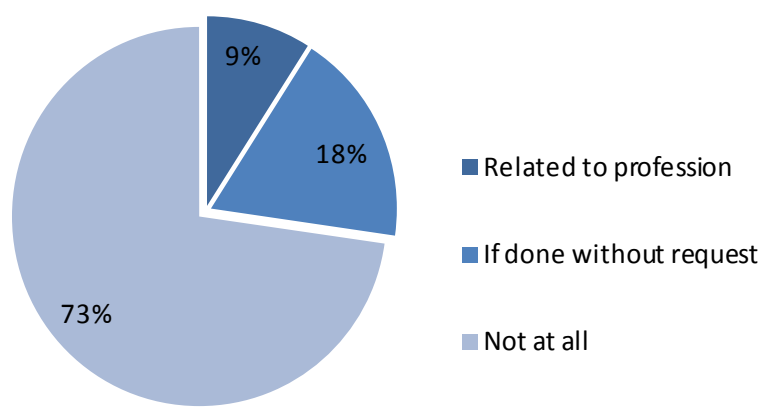

Figure 2. The acceptance of high cost gifts and the causes for their acceptance.

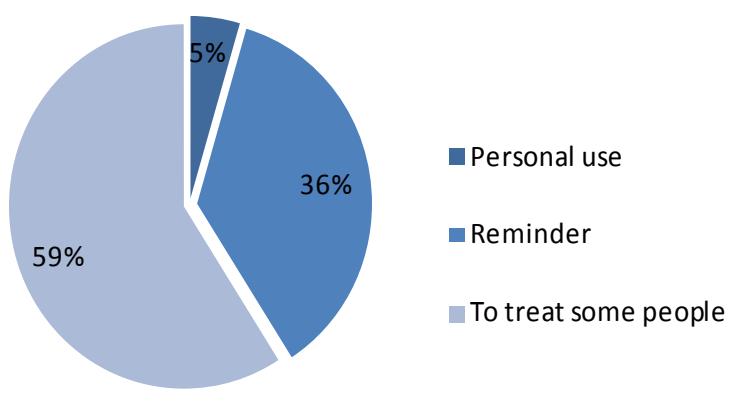

Figure 3. Usage of free sample by physician.

Table 5. The effect of promotion on physicians' prescribing patterns.

\begin{tabular}{|c|c|c|c|}
\hline \multirow{2}{*}{ The question } & \multicolumn{2}{|c|}{ The answer } & \multirow{2}{*}{$\mathrm{P}$ value } \\
\hline & Yes & No & \\
\hline Do you prefer prescribing newer medications? & $17(77 \%)$ & $5(23 \%)$ & 0.0105 \\
\hline $\begin{array}{l}\text { Have you ever stopped the use of a promoted drug that you already prescribed to } \\
\text { many patients if you find that this drug cause many side effects? }\end{array}$ & $21(95 \%)$ & $1(5 \%)$ & 0.000 \\
\hline $\begin{array}{l}\text { Have you ever stopped the use of a promoted drug that you already prescribe } \\
\text { due to drug ineffectiveness? }\end{array}$ & $21(95 \%)$ & $1(5 \%)$ & 0.000 \\
\hline Do you shift prescribing between generic drugs from one company to another? & $18(82 \%)$ & $4(18 \%)$ & 0.0028 \\
\hline Do you shift prescribing from brand to generic drugs? & $16(72 \%)$ & $6(28 \%)$ & 0.033 \\
\hline Do you shift prescribing from generic to brand drugs? & $15(68 \%)$ & $7(32 \%)$ & 0.088 \\
\hline
\end{tabular}


Table 6. Correlation of different studied parameters among each other.

\begin{tabular}{|c|c|c|c|}
\hline First parameter & Second Parameter & Correlation coefficient & $P$ value \\
\hline \multirow{10}{*}{$\begin{array}{l}\text { Number of MRs who visit the } \\
\text { physician in his/her clinic }\end{array}$} & Number of patients & 0.511* & 0.013 \\
\hline & Shifting from Generic to generic drugs & 0.098 & 0.657 \\
\hline & Shifting from Generic to brand & 0.221 & 0.311 \\
\hline & Shifting from Brand to generic & 0.001 & 0.995 \\
\hline & Gift acceptance & 0.323 & 0.133 \\
\hline & Acceptance of low cost gift & 0.115 & 0.602 \\
\hline & Acceptance of high cost gift & 0.257 & 0.236 \\
\hline & Acceptance of continuous supply of low cost gifts & 0.191 & 0.384 \\
\hline & Continuous supply of high cost gift is justifiable & 0.438* & 0.037 \\
\hline & Knowledge improved by attending meetings & 0.277 & 0.2 \\
\hline \multirow{10}{*}{$\begin{array}{l}\text { Physician acceptance } \\
\text { of gifts in general }\end{array}$} & Number of patients & 0.273 & 0.207 \\
\hline & Number of MRs & 0.323 & 0.133 \\
\hline & Shifting from Generic to generic drugs & 0.368 & 0.084 \\
\hline & Shifting from Generic to brand & -0.132 & 0.547 \\
\hline & Shifting from Brand to generic & 0.273 & 0.207 \\
\hline & Acceptance of low cost gifts & 0.247 & 0.255 \\
\hline & Acceptance of high cost gifts & 0.195 & 0.372 \\
\hline & Acceptance of continuous supply of low cost gifts & $0.589 * *$ & 0.003 \\
\hline & Continuous supply of high cost gifts is justifiable & $0.538^{* *}$ & 0.008 \\
\hline & Knowledge improved by meetings & $0.462 *$ & 0.026 \\
\hline \multirow{9}{*}{ Acceptance of low cost gifts } & Number of patients & 0.1 & 0.651 \\
\hline & Number of MR & 0.115 & 0.602 \\
\hline & Shifting from Generic to generic drugs & $0.673 * *$ & 0.000 \\
\hline & Shifting from Generic to brand & 0.168 & 0.443 \\
\hline & Shifting from Brand to generic & 0.168 & 0.443 \\
\hline & Acceptance of high cost gifts & -0.352 & 0.1 \\
\hline & Acceptance of continuous supply of low cost gifts & 0.322 & 0.134 \\
\hline & Continuous supply of high cost gifts is justifiable & -0.168 & 0.443 \\
\hline & Knowledge improved by meetings & 0.215 & 0.323 \\
\hline \multirow{8}{*}{$\begin{array}{l}\text { Acceptance of the physician to low } \\
\text { cost gifts at every visit of MRs }\end{array}$} & Number of patients & 0.041 & 0.852 \\
\hline & Number of MR & 0.191 & 0.384 \\
\hline & Shifting from Generic to generic drugs & 0.25 & 0.251 \\
\hline & Shifting from Generic to brand & -0.172 & 0.432 \\
\hline & Shifting from Brand to generic & $0.422 *$ & 0.045 \\
\hline & Acceptance of high cost gifts & 0.137 & 0.532 \\
\hline & Continuous supply of high cost gifts is justifiable & 0.371 & 0.082 \\
\hline & Knowledge improved by meetings & $0.469 *$ & 0.024 \\
\hline \multirow{7}{*}{ Acceptance of high cost gifts } & Number of patients & 0.32 & 0.136 \\
\hline & Number of MR & 0.257 & 0.236 \\
\hline & Shifting from Generic to generic drugs & -0.292 & 0.177 \\
\hline & Shifting from Generic to brand & -0.078 & 0.723 \\
\hline & Shifting from Brand to generic & 0.122 & 0.581 \\
\hline & Continuous supply of high cost gifts is justifiable & $0.677 * *$ & 0.000 \\
\hline & Knowledge improved by meetings & $0.595^{* *}$ & 0.003 \\
\hline \multirow{6}{*}{$\begin{array}{l}\text { Acceptance of the physician to high } \\
\text { cost gifts at every visit of MRs }\end{array}$} & Number of patients & 0.238 & 0.273 \\
\hline & Number of MR & $0.438 *$ & 0.037 \\
\hline & Shifting from Generic to generic drugs & 0.011 & 0.959 \\
\hline & Shifting from Generic to brand & 0.127 & 0.562 \\
\hline & Shifting from Brand to generic & 0.127 & 0.562 \\
\hline & Knowledge improved by meetings & $0.607 * *$ & 0.002 \\
\hline
\end{tabular}


number of MRs who visit the physician increase the acceptance of high cost gift at every visit of the MRs to the physician clinic also increased. Additionally there is a positive direct correlation between gift acceptance by a physician and the justification of the continuous supply of gifts (low and/or high cost) by MRs to the physicians. Furthermore those who accept high cost gifts consider the administration of high cost gift by MRs at every visit to them is justifiable. Moreover, there is a direct positive correlation between the improvement in physician knowledge by attending conferences and physician acceptance to gifts especially high cost gifts, and low cost gifts at every visit of the MRs to the physician clinic. Most important finding of this study is the direct positive correlation of physician acceptance of low cost gifts \& shifting in the prescribing behavior from generic to other generic drugs, while shifting from brand to generic drugs was better correlated with the continuous supply of low cost gifts to physician

\section{Discussion}

There is a large increase in pharmaceutical promotion in Iraq especially since 2003, however, there is no any research exploring the physician interactions with pharmaceutical companies and their MRs through gifts offering and the effect of such interaction on the attitudes and prescribing behaviors of physicians in Iraq.

This study showed that Iraqi physicians were routinely visited by MRs in a range of 1 - 3 visit/day, By comparison the visits of MRs to physicians in Iraq is the highest among many other developed (Canada, and Newzeland) [10] [11] and developing countries (Yemen, Libya and Tunisia) [12]-[14], additionally it was found in this study that the number of MRs who visit physicians is directly correlated with the number of patients in the physician's clinic, similarly some other studies found a direct correlation between the number of MRs and the number of patients visiting the physician's clinic [15], this can be easily explained in that pharmaceutical companies through their MRs targeting famous physicians and those who are heavy prescribers [16] to ensure a high commercial benefit through prescribing the drug by such physicians to greater number of patients.

The result of this study showed a non significant improvement in the clinical knowledge of the physician by attending conferences or meetings that sponsored by drug companies. However half of the participated physicians preferred the travel abroad to get educational and clinical knowledge by attending such conferences, although we assume in our question that the scientific speaker is the same one. Additionally it was found that there is a direct positive correlation between physicians who find that their knowledge is improved by attending conferences and the acceptance of gifts by a physician especially high cost gifts, and low cost gifts if they are supplied to the physician on regular basis. Therefore the entertainment or other hospitality, and any gifts offered to members of the medical and allied professions by the sponsored drug company, is the most suitable explanation for such preference by the Iraqi physicians to attend sponsored conferences outside Iraq. On the other hand, this study showed that physicians significantly changed their prescribing pattern after attending such conferences, which may mean that prescribing behavior influenced by the effect of conference hospitality rather than by the clinical knowledge from that conference. Similarly it is well know that attending sponsored conferences is one of the influencing factors for physicians to change their prescribing patterns [17] [18], this change in prescribing behavior can be considered as a type of conflict of interest which in turn result in a compromised loyalty of the physician to the patient and thus decrease the ability of the physician to act for benefiting the patient [8] [19].

Regarding Gift acceptance, this study showed that there is a non significant difference among physicians who accept gifts (41\%) and those who consider that behavior as non ethical nor acceptable (59\%). While in other studies, larger percent (66\% - 80\%) of physicians accept gifts from drug companies [20] [21]. Mean while most of the Iraqi physicians (91\%) accept low cost gifts. Furthermore 68\% of participated physicians accept low cost gifts from MRs even if it is offered at every visit of MR to their clinic, this high percentage of physicians who accept low cost gifts means that some of the participated physicians in this study didn't answer the $1^{\text {st }}$ general question about gift acceptance in a real way either because they really know that gift acceptance is un ethical or they ashamed from such behavior, so they don't like that their behavior to be known to the public. Then if anyone asks why we assumed that participated physicians answered the question of low cost gift in a real way and not other questions? This can be answered in that some medical guidelines considering the acceptance of small low cost gift permissible [22] besides that most physicians make distinctions about the ethical appropriateness of gifts on monetary basis [18] so they feel that small gifts do not significantly alter or influence their prescribing behavior [23], so they are not ashamed from announcing their acceptance of low cost gifts. However, social sci- 
ence research demonstrates that the impulse to reciprocate for even small gifts is a powerful influence on people's behavior. Individuals receiving gifts are often unable to remain objective; they reweigh information and choices in light of the gift [24]. Furthermore, this study showed that there is a positive correlation between gift acceptance by a physician and the justification of the continuous supply of gifts (low and/or high cost) by MRs to the physicians, this result also confirm our assumption in that physicians didn't answer the question of gift acceptance in a real way.

For high cost gifts, this study showed that $41 \%$ of physicians accept high cost gifts, while in USA a lower percent (25.4\%) of physicians consider the acceptance of high cost gift is appropriate and ethical [25], despite the higher percent of unethical acceptance for high cost gifts among Iraqi physicians than American physicians, but this difference may be resulted from the higher percent of surgeons who participated in the current study, at which surgeons are one of the most common specialist physicians who accept gifts [25].

This study also showed that the least acceptable form of industrial gifts to physicians is the high cost gift which supplied by MRs on a regular basis for the physician, this result may give us a hope in that Iraqi physicians still possess the ethics of medicine and may focus in their work to their patient rather than their financial benefit. Meanwhile it was found that physician acceptance of high cost gift at every visit of the MRs to the physician clinic is well correlated by the number of MRs visiting the physician clinic, this can be explained in that physicians who have a positive attitude toward industrial marketing activities like interaction with MRs usually show an acceptance of gifts [25].

Regarding free samples, the gift of a free drug may be further problematic even though most clinicians and policymakers believe free samples are the single most acceptable marketing gift from the pharmaceutical industry [26]. In this study it is found that there is a significant usage of free samples by physicians (59\%) to treat some people, although the purpose of free sample is for product recall, but these samples are sometimes used to initiate treatment for a new patient or, in some cases, to provide medication for a poor patient who cannot afford to buy it. Ethical questions are always being asked about whether it is ethical to give away free samples or to give medicines for free to the customers [7]. Nonetheless, according to the situation in Iraq at which approximately $19 \%$ of people are below poverty line (according to the statistics of Iraq's human rights ministry), this make the usage of free sample to treat some people may be ethically acceptable.

It is very important to mention that gifts whether it is cheap or expensive will cost the pharmaceutical company money that surely will be added to the cost of medication [27], that in turn have a negative economic consequence not only to the patient but also to the national budget especially in countries like Iraq at which medications are given freely to all people who treated in Iraqi public hospitals.

This study showed that Iraqi physicians significantly prefer prescribing new medications. There are some other studies showed that physicians who are interested in drug promotion and have positive attitude toward drug companies and their promotion rapidly adopt prescription of new medications [28]. Additionally general practitioner physicians often affected by pharmaceutical companies promotion and prescribe new expensive drugs even if they have no advantages compared with the older alternatives [29]-[32]. However, in contrast with this study specialist physicians less likely to adopt new medications depending on MRs or other commercial source of information [33], this difference may be attributed to the frequent contact of Iraqi specialist physicians with a drug representative at which this contact is associated with a greater willingness to prescribe new drugs that might not be clinically indicated [34]. Additionally in this regard more than $95 \%$ of participated physicians stated that they stop prescribing these new drugs either due to their ineffectiveness or due to their side effects which means that this rapid adoption of new medications is not based on clinical evidence but rather it solely based on commercial source of information, this irrational prescribing behavior is so dangerous and may lead to many undesirable outcomes for the patient. On the other hand the result of this study showed that physicians significantly shift prescribing among generic drugs, and also from brand to generic drugs, this means that prescribing behavior of Iraqi specialist physicians is always influenced by MRs, which is unlike other studies which showed that most physicians didn't feel that their prescribing pattern will be influenced by MRs [35].

This difference could be resulted from the indirect way of questioning in this study, which may provide a more real result than other studies. There are many explanations for such change in prescribing behavior, $1^{\text {st }}$ of all physicians may be affected by the promotional information or by MRs gifts, but since one of the findings of this study, is the direct positive correlation of physician acceptance of low cost gifts and shifting in the prescribing behavior among generic drugs, while shifting from brand to generic drugs was better correlated with the continuous supply of low cost gifts to physician, this means that gifts rather than clinical information is most 
important factor for such influence or change in prescribing behavior, similarly it is well known that gifts is the main cause for changing and influencing prescribing patterns [36]. Anyhow physicians insisted in that shifting among drugs had no negative impact on patient care because influence occurred only when products are equal [27], even if this assumption is true, shifting among different generic drugs by the physician, putting many question marks on such behavior and simply it can be concluded that prescribing pattern of Iraqi physicians is negatively affected by promotional tactics.

Although this study is limited by its small sample size, but it rings a bell of danger by the non ethical interaction between pharmaceutical companies and physicians in Iraq, which negatively affect physician prescribing behavior and in turn negatively affect patients' health, so it is recommended to establish a national guidelines for drug promotion in Iraq to limit such un ethical ways for drug promotion like gifts, free samples and invitation to sponsored conferences.

\section{Conclusion}

In conclusion, Iraqi physicians accept various types of gifts from pharmaceutical companies; this can influence physician prescribing pattern and result in early adoption to prescribe newly medications depending on promotional information even in absence of clinical evidence about the drug effectiveness or side effects, which may result in undesirable outcomes to the patient.

\section{References}

[1] Parker, R.S. and Pettijohn, C.E. (2003) Ethical Conditions in the Use of Direct-To-Consumer Advertising and Pharmaceutical Promotions: The Impact on Pharmaceutical Sales and Physicians. Journal of Business Ethics, 48, 279-290. http://dx.doi.org/10.1023/B:BUSI.0000005783.58142.6e

[2] Handa, M., Vohra, A. and Srivastava, V. (2013) Perception of Physicians towards Pharmaceutical Promotion in India. Journal of Medical Marketing: Device, Diagnostic and Pharmaceutical Marketing, 13, 82-92. http://dx.doi.org/10.1177/1745790413480519

[3] Chiu, H. (2005) Selling Drugs: Marketing Strategies in the Pharmaceutical Industry and Their Effect on Healthcare and Research. Explorations: Undergraduate Research, 8, 89-94.

[4] Caudill, T.S., Johnson, M.S., Rich, E.C. and McKinney, W.P. (1996) Physicians, Pharmaceutical Sales Representatives, and the Cost of Prescribing. Archives of Family Medicine, 5, 201-206. http://dx.doi.org/10.1001/archfami.5.4.201

[5] Schramm, J., Andersen, M., Vach, K., Kragstup, J., Kampmann, J.P. and Ondergaard, J.S. (2007) Promotional Methods Used by Representatives of Drug Companies: A Prospective Survey in General Practice. Scandinavian Journal of Primary Health Care, 25, 93-97. http://dx.doi.org/10.1080/02813430701339659

[6] Jibson, M.D. (2007) Interactions between Physicians and Industry: A Guide for Clinicians. FOCUS: The Journal of Lifelong Learning in Psychiatry, 5, 398-406.

[7] Noordin, M.I. (2012) Ethics in Pharmaceutical Issues, Contemporary Issues in Bioethics.

[8] Davis, M. (1982) Conflict of Interest. Business and Professional Ethics Journal, 1, 17-27. http://dx.doi.org/10.5840/bpej1982149

[9] Redelmeier, D.A. (2009) On the Psychology of Pharmaceutical Industry Gifts to Physicians. Journal of General Internal Medicine, 25, 7-8. http://dx.doi.org/10.1007/s11606-009-1157-8

[10] Strang, D., Gagnon, M., Molloy, W., Bedard, M., Darzins, P., Etchells, E., et al. (1996) National Survey on the Attitudes of Canadian Physicians towards Drug-Detailing by Pharmaceutical Representatives. Annals (Royal College of Physicians and Surgeons of Canada), 29, 474-478.

[11] Thomson, A.N., Craig, B.J. and Barham, P.M. (1994) Attitudes of General Practitioners in New Zealand to Pharmaceutical Representatives. British Journal of General Practice, 44, 220-223.

[12] Al-Areefi, M.A., Hassali, M.A. and Ibrahim, M.I.B.M. (2013) Physicians’ Perceptions of Medical Representative Visits in Yemen: A Qualitative Study. BMC Health Services Research, 13, 331. http://dx.doi.org/10.1186/1472-6963-13-331

[13] Alssageer, M.A. and Kowalski, S.R. (2012) A Survey of Pharmaceutical Company Representative Interactions with Doctors in Libya. Libyan Journal of Medicine, 7, 18556. http://dx.doi.org/10.3402/ljm.v7i0.18556

[14] Ben Abdelaziz, A., Harrabi, I., Rahmani, S., Ghedira, A., Gaha, K. and Ghannem, H. (2003) Attitudes of General Practitioners to Pharmaceutical Sales Representatives in Sousse. Eastern Mediterranean Health Journal, 9, 1075-1083.

[15] Vancelik, S., Beyhun, N.E., Acemoglu, H. and Calikoglu, O. (2007) Impact of Pharmaceutical Promotion on Prescrib- 
ing Decisions of General Practitioners in Eastern Turkey. BMC Public Health, 25, 122. http://dx.doi.org/10.1186/1471-2458-7-122

[16] Williams, P.A., Cockerill, R. and Lowy, F.H. (1995) The Physician as Prescriber: Relations between Knowledge about Prescription Drugs, Encounters with Patients and the Pharmaceutical Industry, and Prescription Volume. Health and Canadian Society, 3, 135-166.

[17] Moynihan, R. (2003) Who Pays for the Pizza? Redefining the Relationships between Doctors and Drug Companies. 1: Entanglement. BMJ, 326, 1189-1192. http://dx.doi.org/10.1136/bmj.326.7400.1189

[18] Brett, A.S., Burr, W. and Moloo, J. (2003) Are Gifts from Pharmaceutical Companies Ethically Problematic? A Survey of Physicians. Archives of Internal Medicine, 163, 2213-2218. http://dx.doi.org/10.1001/archinte.163.18.2213

[19] Rodwin, M.A. (1993) Medicine, Money and Morals: Physicians’ Conflict of Interest. Oxford University Press, Oxford.

[20] McNeill, P.M., Kerridge, I.H., Henry, D.A., Stokes, B., Hill, S.R., Newby, D., Macdonald, G.J., Day, R.O., Maguire, J. and Henderson, K.M. (2006) Giving and Receiving of Gifts between Pharmaceutical Companies and Medical Specialists in Australia. Internal Medicine Journal, 36, 571-578. http://dx.doi.org/10.1111/j.1445-5994.2006.01151.X

[21] Alosaimi, F., Alkaabba, A., Qadi, M., Albahlal, A., Alabdulkarim, Y., Alabduljabbar, M. and Alqahtani, F. (2013) Acceptance of Pharmaceutical Gifts. Variability by Specialty and Job Rank in a Saudi Healthcare Setting. Saudi Medical Journal, 34, 854-860.

[22] McMurray, R.J., Clarke, O.W., Barrasso, J.A., Clohan, D.B., Epps Jr., C.H. and Glasson, J. (1991) Gifts to Physicians from Industry. JAMA, 265, 501. http://dx.doi.org/10.1001/jama.1991.03460040077034

[23] Brennan, T.A., Rothman, D.J., Blank, L., Blumenthal, D., Chimonas, S.C., Cohen, J.J., Goldman, J., Kassirer, J.P., Kimball, H., Naughton, J. and Smelser, N. (2006) Health Industry Practices That Create Conflicts of Interest: A Policy Proposal for Academic Medical Centers. JAMA, 295, 429-433. http://dx.doi.org/10.1001/jama.295.4.429

[24] Dana, J. and Loewenstein, G. (2003) A Social Science Perspective on Gifts to Physicians from Industry. JAMA, 290, 252-255. http://dx.doi.org/10.1001/jama.290.2.252

[25] Korenstein, D., Keyhani, S. and Ross, J.S. (2010) Physician Attitudes toward Industry: A View across the Specialties. Archives of Surgery, 145, 570-577. http://dx.doi.org/10.1001/archsurg.2010.75

[26] Morgan, M.A., Dana, J., Loewenstein, G., Zinberg, S. and Schulkin, J. (2006) Interactions of Doctors with the Pharmaceutical Industry. Journal of Medical Ethics, 32, 559-563. http://dx.doi.org/10.1136/jme.2005.014480

[27] Chimonas, S., Brennan, T.A. and Rothman, D.J. (2007) Physicians and Drug Representatives: Exploring the Dynamics of the Relationship. Society of General Internal Medicine, 22, 184-190.

[28] Wazana, A. (2000) Physicians and the Pharmaceutical Industry: Is a Gift Ever Just a Gift? JAMA, 283, 373-380. http://dx.doi.org/10.1001/jama.283.3.373

[29] Rutledge, P., Crookes, D., McKinstry, B. and Maxwell, S.R. (2003) Do Doctors Rely on Pharmaceutical Industry Funding to Attend Conferences and Do They Perceive That This Creates a Bias in Their Drug Selection? Results from a Questionnaire Survey. Pharmacoepidemiology and Drug Safety, 12, 663-667. http://dx.doi.org/10.1002/pds.884

[30] Blumenthal, D. (2004) Doctors and Drug Companies. The New England Journal of Medicine, 351, 1885-1890. http://dx.doi.org/10.1056/NEJMhpr042734

[31] Abbasi, K. and Smith, R. (2003) No More Free Lunches. BMJ, 326, 1155-1156. http://dx.doi.org/10.1136/bmj.326.7400.1155

[32] Peay, M., Peay, Y. and Edmund, R. (1990) Patterns of Preference for Information Sources in the Adoption of New Drugs by Specialists. Social Science and Medicine, 31, 467-476.

[33] Norris, P., Herxheimer, A., Lexchin, J. and Mansfield, P. (2004) Drug Promotion: What We Know, What We Have Yet to Learn: Reviews of Materials in the WHO/HAI Database on Drug Promotion. WHO/EDM/PAR/2004.3.

[34] Watkins, C., Moore, L., Harvey, I., Carthy, P., Robinson, E. and Brawn, R. (2003) Characteristics of General Practitioners Who Frequently See Drug Industry Representatives: National Cross Sectional Study. BMJ, 326, 1178-1179. http://dx.doi.org/10.1136/bmj.326.7400.1178

[35] Steunman, M., Shilpak, M. and McPhee, S. (2001) Of Principles and Pens: Attitudes and Practices of Medicine House Staff toward Pharmaceutical Industry Promotions. The American Journal of Medicine, 110, 551-557. http://dx.doi.org/10.1016/S0002-9343(01)00660-X

[36] Sultana, S. and Khosru, K.H. (2011) Practice of Using Gifts as Promotional Materials for Marketing of Pharmaceutical Products in Bangladesh: A Survey Conducted on General Physicians and Representatives from Pharmaceutical Companies. Stamford Journal of Pharmaceutical Sciences, 4, 13-18. 


\section{Appendix: The Questions of the Questionnaire}

Part 1: (questions regarding number of patients and medical representatives)

1. How many medical representative visits you in your clinic per day?
A. Less than $1 /$ day
B. 1 - 3/day
C. 3 - $5 /$ day
D. more than $5 /$ day

2. How many patients visit you in your clinic daily?
A. Less than $5 /$ day
B. $5-10 /$ day
C. 10 - 20/day
D. More than 20

Part 2: (Questions regarding conferences and meetings)

1. Do you think that your medical knowledge is improved by meetings and conferences that sponsored by drug companies?
A. Yes, always
B. Yes, many times
C. Yes, some times (slightly)
D. Not at all

2. Do you change your clinical practice after attending conferences and meetings?
A. Yes, always
B. Yes, many times
C. Yes, some times (slightly)
D. Not at all

3. Regarding conferences for new drug information (assuming that the talk was done by the same professor) you prefer attending:
A. Inside Iraq
B. Outside Iraq

Part 3: (questions regarding gift acceptance)

1. Do you think that gifts from drug companies are acceptable?
A. Yes
B. No

2. Do you think that low cost gifts like pens for drug promotion from drug companies are acceptable?
A. Yes
B. No

3. Do you think that the continuous supply of low cost gifts to the physician at every visit of the medical representative is justifiable?
A. Yes
B. No

4. Do you think that high cost recreational gifts (Like Laptops, mobiles and LCD) are justifiable in drug promotion?
A. No
B. Yes, If yes then (Always or Sometimes) 
5. Do you think that the continuous supply of high cost gifts to the physician at every visit of the medical representative is justifiable?
A. No
B. Yes, If Yes, then
B1. only if they are related to my profession
B2. what ever the gift if the company gives it without physician request

6. How you use free medical samples?
A. As reminder
B. To treat some people
C. For personal use

Part 4: (Questions regarding prescribing Pattern)

1. Do you prefer prescribing new medications?
A. Yes
B. No

2. Have you ever stopped the use of a promoted drug that you already prescribed to many patients if you find that this drug cause many side effects?
A. Yes
B. No

3. Have you ever stopped the use of a promoted drug that you already prescribe due to drug ineffectiveness?
A. Yes
B. No

4. Do you shift your drug prescribing from one company to another (If both were generic)?
A. Yes
B. No

5. Do you shift your drug prescribing from one company to another (If the $1^{\text {st }}$ one brand and the other generic)?
A. Yes
B. No

6. Do you shift your drug prescribing from one company to another (If the $1^{\text {st }}$ one generic and the other brand)?
A. Yes
B. No 
Scientific Research Publishing (SCIRP) is one of the largest Open Access journal publishers. It is currently publishing more than 200 open access, online, peer-reviewed journals covering a wide range of academic disciplines. SCIRP serves the worldwide academic communities and contributes to the progress and application of science with its publication.

Other selected journals from SCIRP are listed as below. Submit your manuscript to us via either submit@scirp.org or Online Submission Portal.
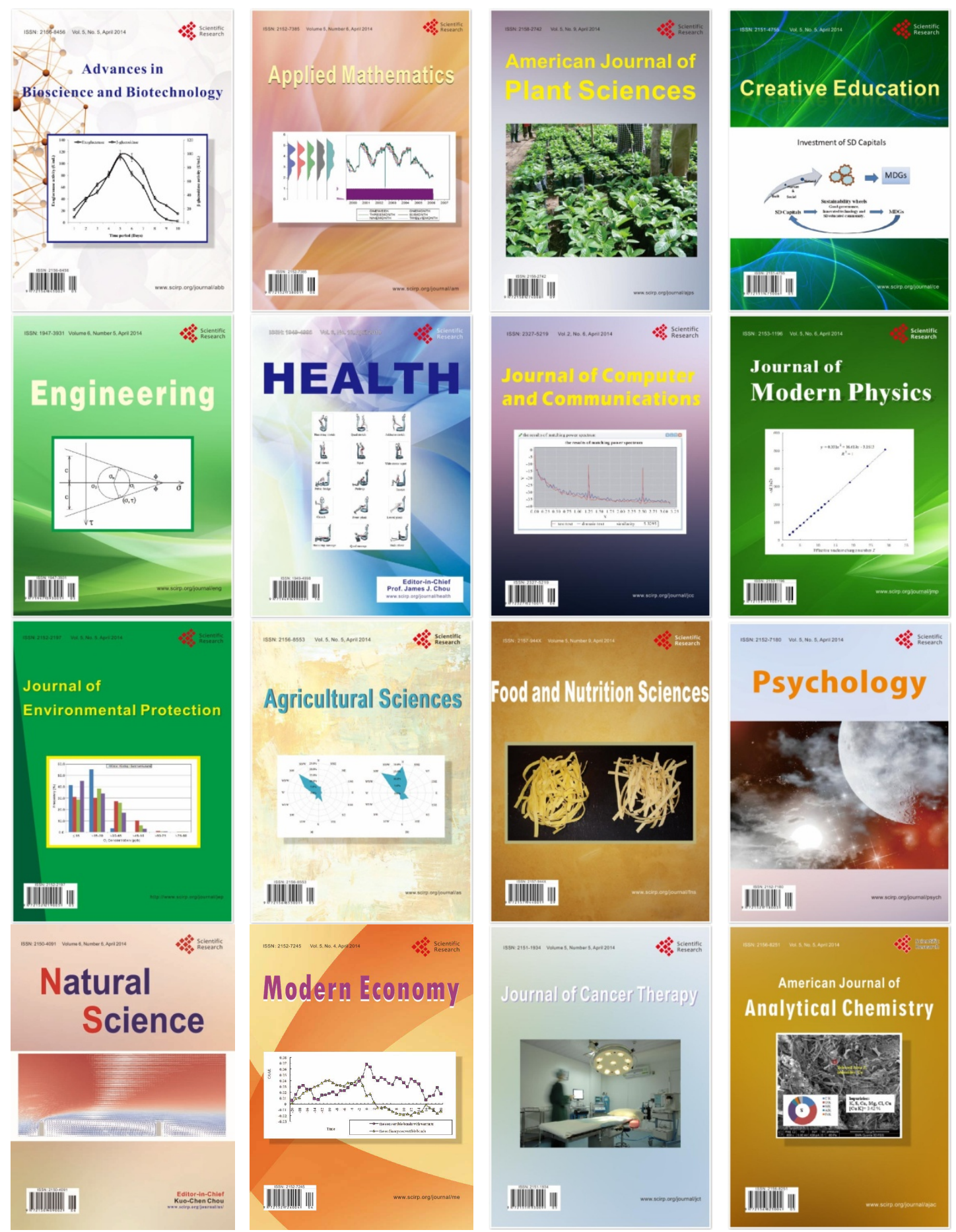